\title{
Hypoxia-Induced MicroRNA-429 Promotes Differentiation of MC3T3-E1 Osteoblastic Cells by Mediating ZFPM2 Expression
}

\author{
Jiang Huang Jianguang Peng Guanglei Cao Shibao Lu Limin Liu Zheng Li \\ Meng Zhou Mingli Feng Huiliang Shen \\ Department of Orthopedics, Xuanwu Hospital, Capital Medical University, Beijing, China
}

\author{
Key Words \\ Hypoxia • MiR-429 • Differentiation • ZFPM2
}

\begin{abstract}
Background/Aims: Hypoxia has been reported to regulate osteoblastic differentiation of bone cells and cartilage development. However, information concerning the molecular mechanisms remains largely unknown. Methods: The expression of miR-429 was evaluated by quantitative real-time PCR analysis. To test whether miR-429 directly regulate the expression level of ZFPM2 at transcription level, dual-luciferase reporter gene assay was performed. Western blotting was performed to detect osteogenesis related protein expression. The cell proliferation, apoptosis, alkaline phosphatase activity and matrix mineralization were performed to assess the functions of miR-429 in vitro and in vivo the effects of miR-429 on fracture healing. Results: Expression of miR-429 was increased in MC3T3-E1 cells treated with $200 \mu \mathrm{M} \mathrm{CoCl}$, by qRT-PCR, and overexpression of miR-429 promoted cell differentiation, and enhanced alkaline phosphatase activity and matrix mineralization. Luciferase reporter assays suggested that miR-429 directly targets the 3'UTR of ZFPM2. In addition, knockdown of ZFPM2 could phenocopy the effects of miR-429 expression. Furthermore, overexpression of ZFPM2 in miR-429-expressing MC3T3-E1 cells suppressed cell differentiation. Conclusions: Our results provide valuable insight into the potential role of hypoxia in regulation of osteoblastic cell differentiation.
\end{abstract}

(C) 2016 The Author(s)

Published by S. Karger AG, Basel

\section{Introduction}

Tibial pilon fractures are a major health problem worldwide. The major causes of fractures are motor vehicle accidents and falls from a height [1,2]. Despite effective therapeutic strategies, such as intramedullary nails and plates, used to improve healing

J. Huang and J. Peng contributed to this study equally. 


\section{Cellular Physiology Cell Physiol Biochem 2016;39:1177-1186 \begin{tabular}{l|l|l} 
and Biochemistry Published online: September 01, 2016 & $\begin{array}{l}\text { (c) 2016 The Author(s). Published by S. Karger AG, Basel } \\
\text { www.karger.com/cpb }\end{array}$ \\
\hline
\end{tabular} \\ Huang et al.: MiR-429 Promote Osteoblastic Differentiation}

potential both for acute fractures and nonunions, high rates of delayed union or nonunion have been reported [3]. Our previous study showed that hypoxia could accelerate bone union and acute tibial fracture healing [4]. However, the precise mechanisms of hypoxia and its involvement in osteoblastic differentiation are still poorly understood.

MicroRNAs (miRNAs) are small endogenous non-coding RNAs, which bind to target mRNAs with complementary sequences to suppress the translation and stabilization of the target mRNA $[5,6]$. Mature miRNAs derive from a complex process, where a primitive form of miRNA (pri-miR) is transcribed by RNA pol II and cleaved by the ribonuclease DROSHA in the nucleus to originate a precursor miRNA (pre-miR), which is exported to the cytoplasm or the endoplasmic reticulum and undergoes a second cleavage by a RNase III endonuclease, Dicer, to become approximately 22 nucleotides length miRNA duplex [7]. Emerging evidence suggests that miRNAs play critical roles in many cellular processes, including cell growth, invasion, metabolism and differentiation [8-11]. It was recently revealed that miRNAs have been involved in mediating the osteogenic differentiation of osteoblasts and mesenchymal stem cells (MSCs). MiR-143 and miR-145 were decreased in osteogenic differentiation, and their overexpression suppressed osteogenic differentiation by targeting Osterix and Sp7 transcription factor 7 (Sp7) in vitro, respectively $[12,13]$. MiR-155 is induced by Interferon- $\beta$ and inhibits osteoclast differentiation by targeting suppressor of cytokine signaling 1 (Socs1) and microphthalmia-associated transcription factor (Mitf), two essential regulators of osteoclastogenesis [14]. In addition, miR-29b was increased in osteoblast differentiation, and ectopic expression of miR-29b promoted osteogenesis by directly down-regulating the expression of collagen type I alpha 1 (COL1A1), collagen type V alpha 3 (COL5A3), and collagen, type IV, alpha 2 (COL4A2) [15].

In this study, we focused on miR-429 that is significantly upregulated under hypoxia in human endothelial cells [16]. To examine osteoblast differentiation in MC3T3-E1 cells, we found that miR-429 was upregulated under hypoxia. Furthermore, gain-of-function experiments indicated that miR-429 promoted osteogenic differentiation by negatively regulating the expression of ZFPM2. Our results suggest that miR-429 is a novel positive regulator of osteogenesis and provide a new mechanism for understanding accelerated fracture healing under hypoxia.

\section{Materials and Methods}

\section{Cell culture and drug treatment}

The murine pre-osteoblastic cell line MC3T3-E1 was obtained from ATCC (Manassas, VA, USA). The cells were cultured in $\alpha$-minimum essential medium (Life Technologies, Grand Island, NY, USA) supplemented with $10 \%$ fetal bovine serum (Life Technologies), 100 units $/ \mathrm{ml}$ of penicillin and $100 \mu \mathrm{g} / \mathrm{ml}$ of streptomycin. HEK293T cells were purchased from the Institutes of Biochemistry and Cell Biology (Shanghai, China) and cultured in DMEM supplemented with 10\% fetal bovine serum (Life Technologies), 100 units $/ \mathrm{ml}$ of penicillin and $100 \mu \mathrm{g} / \mathrm{ml}$ of streptomycin. Cells were cultured at $37^{\circ} \mathrm{C}$ in a humidified atmosphere of $5 \% \mathrm{CO}_{2}$.

To mimic the effects of hypoxia, $200 \mu \mathrm{M} \mathrm{CoCl}_{2}$ was added to the medium. Subsequently, the RNA and protein were harvested at the specified times. Osteogenic differentiation of MC3T3-E1 cells was induced by osteogenic medium (complete medium supplemented with $10 \mathrm{mM} \beta$-glycerophosphate and $50 \mu \mathrm{g} / \mathrm{ml}$ ascorbic acid) that was refreshed every 2 days.

Quantitative RT-PCR

Total RNA from tissues and cells was extracted using Trizol as previously described [4]. To measure the mRNA levels of ZFPM2, 500 ng of total RNA was reverse-transcribed into cDNA and then quantified on an ABI 7900HT Fast Real-Time PCR System (Applied Biosystems, Foster City, CA, USA) as previously described [4]. The following primers were used for mRNA detection: ZFPM2: (forward) 5'-ACC GAA GGG ATG TAC CCTG-3', (reverse) 5'-TCG TTG CCT CCC ACT ACAGT-3'. The relative expression level of ZFPM2 mRNA was normalized against $\beta$-actin. Mature miR-429 expression was measured by qRT-PCR using the TaqMan® MicroRNA Reverse Transcription Kit and the TaqMan ${ }^{\circledR}$ MicroRNA Assays (Applied Biosystems, Foster City, 


\section{Cellular Physiology Cell Physiol Biochem 2016;39:1177-1186

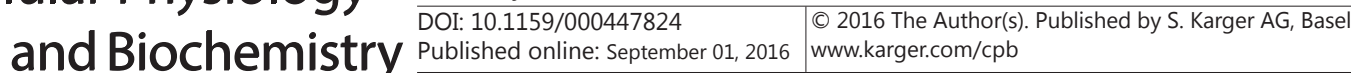 \\ Huang et al.: MiR-429 Promote Osteoblastic Differentiation}

CA, USA) and normalized to U6 according to the manufacturer's instructions. All reactions were performed in triplicate, and three independent assays were performed.

\section{Plasmid construction and lentivirus packaging and infection}

A fragment encoding the pre-miR-429 sequence plus 150 bp flanking both ends was PCR amplified from mouse genomic DNA using the forward primer 5'-AAA GAA TTC AGT CTG CTG TGG CTG TAA CCG-3' and the reverse primer 5'-AAA GGA TCC CCA AAG AGG TGC TAT GAC GAGC-3'. The PCR product was then cloned into the EcoRI/BamHl sites of the pCDH-CMV-MCS-EF1-puro vector (System Biosciences, Mountain View, CA, USA).

The ZFPM2 3' UTR (untranslated region) was PCR amplified from MC3T3-E1 cDNA using the forward primer 5'-AAA AAG CTT TGA GTT ACT AAA GAA AGC AGT CACC-3' and the reverse primer 5'-AAA ACG CGT CGT CTC CAA CAA TTT GGAAT-3'. The PCR product was then cloned into the HindIII/MluI site of pMIRREPORT $^{\mathrm{TM}}$ vector (Ambion, Austin, TX, USA). Mutations of the miR-429 binding sites in the ZFPM2 3' UTR sequence were performed using the QuikChange Site-Directed Mutagenesis Kit (Agilent Technologies, Santa Clara, CA, USA) according to the manufacturer's protocol. All plasmids were confirmed by restriction enzyme digestion and sequencing.

\section{Dual luciferase reporter}

The Lentivirus-mediated miR-429 packaging system was co-transfected into HEK-293T cells with the pPACKH $1^{\text {TM }}$ Lentivector Packaging Kit (System Biosciences) using Lipofectamine ${ }^{\mathrm{TM}} 2000$ (Invitrogen). The supernatant was collected 48 hours post-infection and concentrated by ultracentrifugation. MC3T3-E1 cells were infected with $1 \times 10^{7}$ lentivirus particles in the presence of $8 \mu \mathrm{g} / \mathrm{ml}$ polybrene (Sigma-Aldrich).

Cell proliferation and apoptosis assay

Cell viability was determined by Cell Counting Kit-8 assay (Dojindo, Japan) according to the manufacturer's protocol. In brief, $3 \times 10^{3}$ cells in $100 \mu \mathrm{l}$ of cell suspensions were seeded into each well of 96-well plates and cultured overnight. $10 \mu \mathrm{l}$ of CCK-8 solution was added to each well at $0 \mathrm{~h}, 24 \mathrm{~h}, 48 \mathrm{~h}$ and $72 \mathrm{~h}$, respectively. The optical density (OD) was measured by a microplate reader (Bio-Rad Laboratories) at $450 \mathrm{~nm}$. Apoptosis was evaluated by Annexin V-FITC Apoptosis Detection Kit I (BD Biosciences) following the manufacturer's instructions.

\section{Alkaline phosphatase activity assay}

Alkaline phosphatase activity was determined using the WAKO LabAssay ${ }^{\mathrm{TM}}$ ALP Alkaline Phosphatase Assay Kit (LabAssay TM ALP, Wako, Japan) according to the manufacturer's instructions. Alkaline phosphatase activity was normalized to total protein concentration as assessed by BCA protein assay kit (Thermo Scientific Pierce, USA).

Alizarin Red S staining

To detect the effects of miR-429 and ZFPM2 in mineralization of MC3T3-E1 cells, the cells were washed with PBS and fixed with 4\% paraformaldehyde for $15 \mathrm{~min}$ at room temperature. Fixed cells were stained with 1\% Alizarin Red S solution (Sigma-Aldrich). Pictures were taken of five random non-overlapping fields with a light microscope (Olympus, Tokyo, Japan). Quantification of Alizarin Red S stain was assessed via extraction with Image J software (NIH, Bethesda, MD, USA).

\section{Bioinformatics methods and Luciferase reporter assay}

The potential targets of miR-429 were obtained using computer-aided algorithms from TargetScan and DIANA-TOOLS. MC3T3-E1 cells were transfected with the luciferase reporter plasmids, phRL-TK, together with control or pre-miR-429 using Lipofectamine ${ }^{\mathrm{TM}} 2000$ (Invitrogen) according to the manufacturer's instructions. Luciferase activity was determined $48 \mathrm{~h}$ post-transfection using the Dual Luciferase Reporter Assay System (Promega, Madison, WI, USA) according to the manufacturer's instructions.

\section{Western blotting}

Western blotting was performed as previously described [4]. Briefly, tissues and cells were lysed with RIPA buffer supplemented with complete protease inhibitors (Roche, Mannheim, Germany). Proteins (50 $\mu \mathrm{g}$ ) 


\section{Cellular Physiology Cell Physiol Biochem 2016;39:1177-1186 \begin{tabular}{l|l|l} 
and Biochemistry Published online: September 01, 2016 & $\begin{array}{l}\text { (c) 2016 The Author(s). Published by S. Karger AG, Basel } \\
\text { www.karger.com/cpb }\end{array}$ \\
\hline
\end{tabular} \\ Huang et al.: MiR-429 Promote Osteoblastic Differentiation}

were separated on a 10\% SDS-polyacrylamide gradient gel (Bio Rad Laboratories, Hercules, CA, USA) and transferred to PVDF membrane (Millipore, Billerica, MA). After blocking, blots were incubated with Rabbit polyclonal ZFPM2 antibody (1:200, Sigma-Aldrich), Rabbit Polyclonal GATA4 antibody (1:1000, Abcam), Rabbit polyclonal ALP antibody (1:100, Abcam), Rabbit polyclonal OC antibody (1:100, Thermofisher), or Rabbit polyclonal $\beta$-actin antibody (1:1000, Santa Cruz Biotechnology). Blots were visualized using a chemiluminescence reagent (Millipore, Temecula, CA, USA) in a LAS4000 Luminescent Image Analyzer (GE Healthcare Japan, Japan).

\section{Animal experiments}

This study was performed in accordance with the Capital Medical University Xuanwu Hospital Affiliated with the Capital Medical University with the permit number of 20141126FR. All 5-day-old Swiss mice were obtained from the Laboratory Animal Center of Capital Medical University. The mouse model (8 per group) of bone fracture was performed with a fracture device as previously described [4]. One hundred microliters of lentivirus $\left(1 \times 10^{9} \mathrm{TU} / \mathrm{ml}\right)$ were directly injected into the subcutaneous region of a local fracture. Healing parameters were measured using a Faxitron X-ray machine (MX-20 Specimen Radiography System, Faxitron $\mathrm{X}$-ray Corp) at 28 days as previously described [4].

Statistical analysis

All experiments were run in triplicate and carried out three independent times. Quantitative data were expressed as the mean \pm standard deviation (SD) and were evaluated using two-tailed t-tests. Data were considered significant at a value of $\mathrm{p}<0.05$.

\section{Results}

MiR-429 is induced by CoCl2 in vitro and in vivo

It was previously shown that miR-429 was induced by hypoxia [16], and our in vivo experiments indicated that $\mathrm{CoCl}_{2}$ could promote fracture repair [4]. To investigate the expression of miR-429 under hypoxic conditions in MC3T3-E1 cells, $200 \mu \mathrm{M} \mathrm{CoCl}_{2}$ was added to the medium. HIF-1 $\alpha$ were detected to be induced by $\mathrm{CoCl} 2$ (Fig. 1A). The expression of miR-429 was detected at the specified times, and our results exhibited miR-429 upregulation by $\mathrm{CoCl}_{2}$ in MC3T3-E1 cells, with the peak value at 4 hours (Fig. 1B). Howover, $\mathrm{CoCl}_{2}$ treatment had no significant effect on cell proliferation and apoptosis (Fig. 1C and D). To further confirm the in vitro data, we detected the expression of miR-429 in the fractured bone tissues of mice treated with $\mathrm{CoCl}_{2}$. Consistent with the results in vitro, miR-429 was significantly upregulated at 7 days and remained increased at 28 days (Fig. 1C), suggesting that miR-429 might be involved in fracture healing.

Effects of miR-429 on osteoblast differentiation in MC3T3-E1 cells

To explore the possible biological functions of miR-429, MC3T3-E1 cells were infected with control or miR-429 expressing lentivirus. As shown in Fig. 2A, miR-429 expression levels were significantly increased in cells infected with the miR-429 lentivirus $72 \mathrm{~h}$ later, confirming successful expression of miR-429 by lentivirus in MC3T3-E1 cells. To investigate the effect of miR-429 on osteoblastic differentiation of MC3T3-E1 cells, we measured alkaline phosphatase (ALP) activity after induction with differentiation medium. Our results showed that miR-429 greatly increased ALP activity, with approximately 1.6- and 1.9-fold increased activity at 21 days and 28 days, respectively, compared to the control virus (Fig. 2B). Furthermore, mineralization analysis showed a significant increase in mineralized nodule formation in miR-429 overexpressing cells compared to controls (Fig. 2C). In addition, we detected the effect of miR-429 on ALP, osteocalcin (OC), and Runt-related transcription factor 2 (RUNX2) by Western blot. As shown in Fig. 2D, ALP, OC and RUNX2 expression levels were significantly increased with overexpression of miR-429. Therefore, miR-429 expression promotes osteogenic differentiation in MC3T3-E1 cells. 
Fig. 1. (A) The HIF-1 $\alpha$ expressions in MC3T3-E1 cells were treated without or with $\mathrm{CoCl}_{2}$ treatment at the indicated times. $\beta$-actin was used as a loading control. (B) $\quad$ qRT-PCR analysis of miR429 expression in MC3T3-E1 cells treated with $200 \mu \mathrm{M}$ $\mathrm{CoCl}_{2}$ at the indicated times. (C) Relative expression of miR429 in fractured bone tissues from mice treated with $\mathrm{CoCl}_{2}$ or without $\mathrm{CoCl}_{2}$.

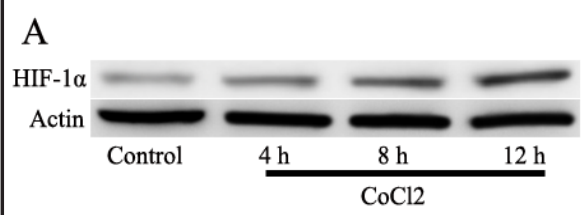

C

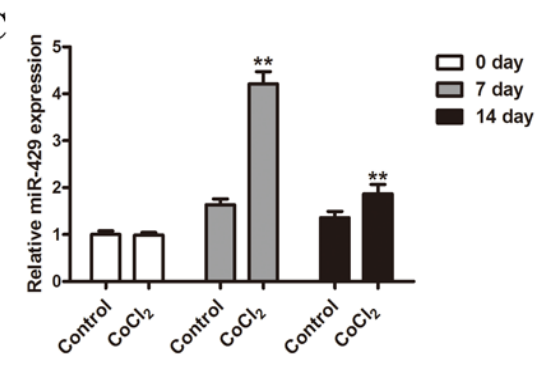

E

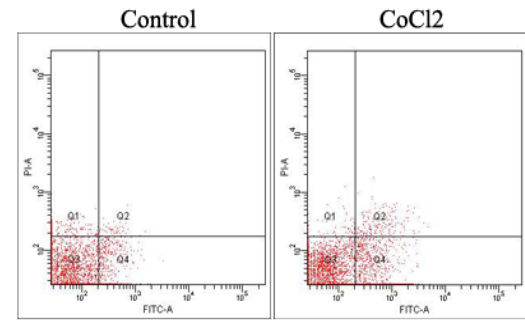

B
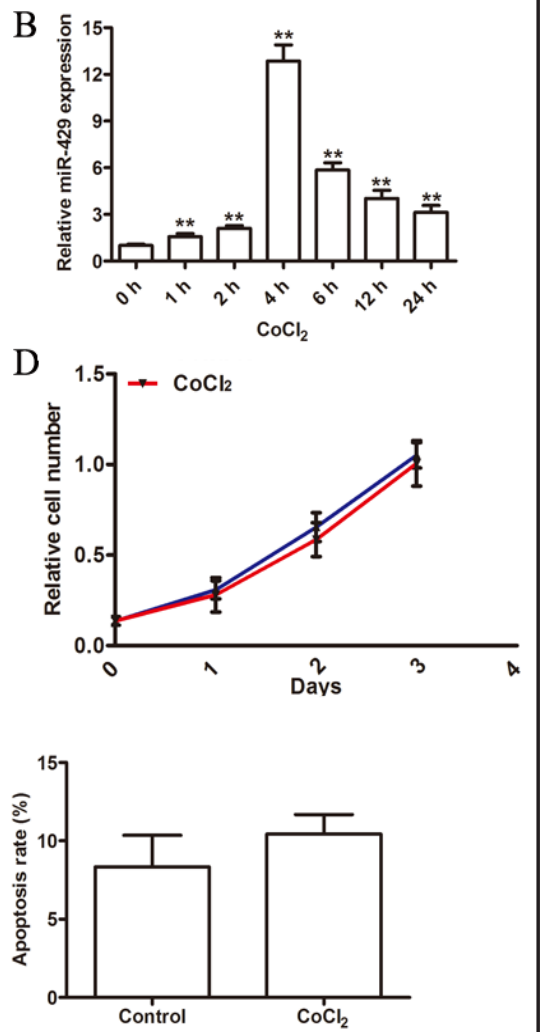

(D) Growth cur-

ves of MC3T3-E1 cells were treated without or with $200 \mu \mathrm{M} \mathrm{CoCl}_{2}$ treatment. (E) Apoptosis of MC3T3-E1 cells treated without or with $200 \mu \mathrm{M} \mathrm{CoCl}_{2}$ treatment was analyzed by flow cytometry. ${ }^{* *}, \mathrm{P}<0.01$.

ZFPM2 is a direct target of miR-429

To identify the molecular mechanisms of miR-429-mediated regulation of osteoblast differentiation, TargetScan and miRBase were used to predict the potential targets of miR429. We found two potential binding sites in the 3' UTR of ZFPM2 at -224 to -230 (sequence 1) and -763 to -769 (sequence 2) (Fig. 3A). To test whether ZFPM2 was a direct target of miR-429, luciferase reporter assays were performed in MC3T3-E1 cells. As shown in Fig. $3 \mathrm{~B}$, miR-429 markedly reduced firefly luciferase activity of reporter plasmids containing the wild-type ZFPM2 3' UTR or ZFPM2-MUT2, whereas luciferase activity was not significantly changed in ZFPM2-MUT1. Furthermore, endogenous ZFPM2 expression at both the mRNA and protein levels was reduced upon miR-429 overexpression in MC3T3-E1 cells (Fig. 3C and D). Moreover, the real-time PCR assay showed that the mRNA level of ZFPM2 was decreased and inversely correlated with miR-429 expression in MC3T3-E1 cells treated with $\mathrm{CoCl} 2$. These results suggested that miR-429 binding site 1 played a functionally significant role in the regulation of ZFPM2 expression.

\section{ZFPM2 silencing mimics the effects of miR-429}

In order to confirm whether miR-429-mediated-osteoblast differentiation is directly related to downregulation of ZFPM2, cells were transfected with ZFPM2 small interfering RNA (siRNA). As shown in Fig. 4A, the effects of ZFPM2 knockdown was confirmed by Western blot, and siRNA2 exhibited the best knockdown efficiency (Fig. 4A). The siRNA2 targeting ZFPM2 was named siZFPM2 and used for subsequent experiments. Knockdown of ZFPM2 in MC3T3-E1 cells increased the ALP activity compared to the negative control (NC) (Fig. 4B). Mineralization was significantly higher at 21 days in the ZFPM2 knockdown cells 


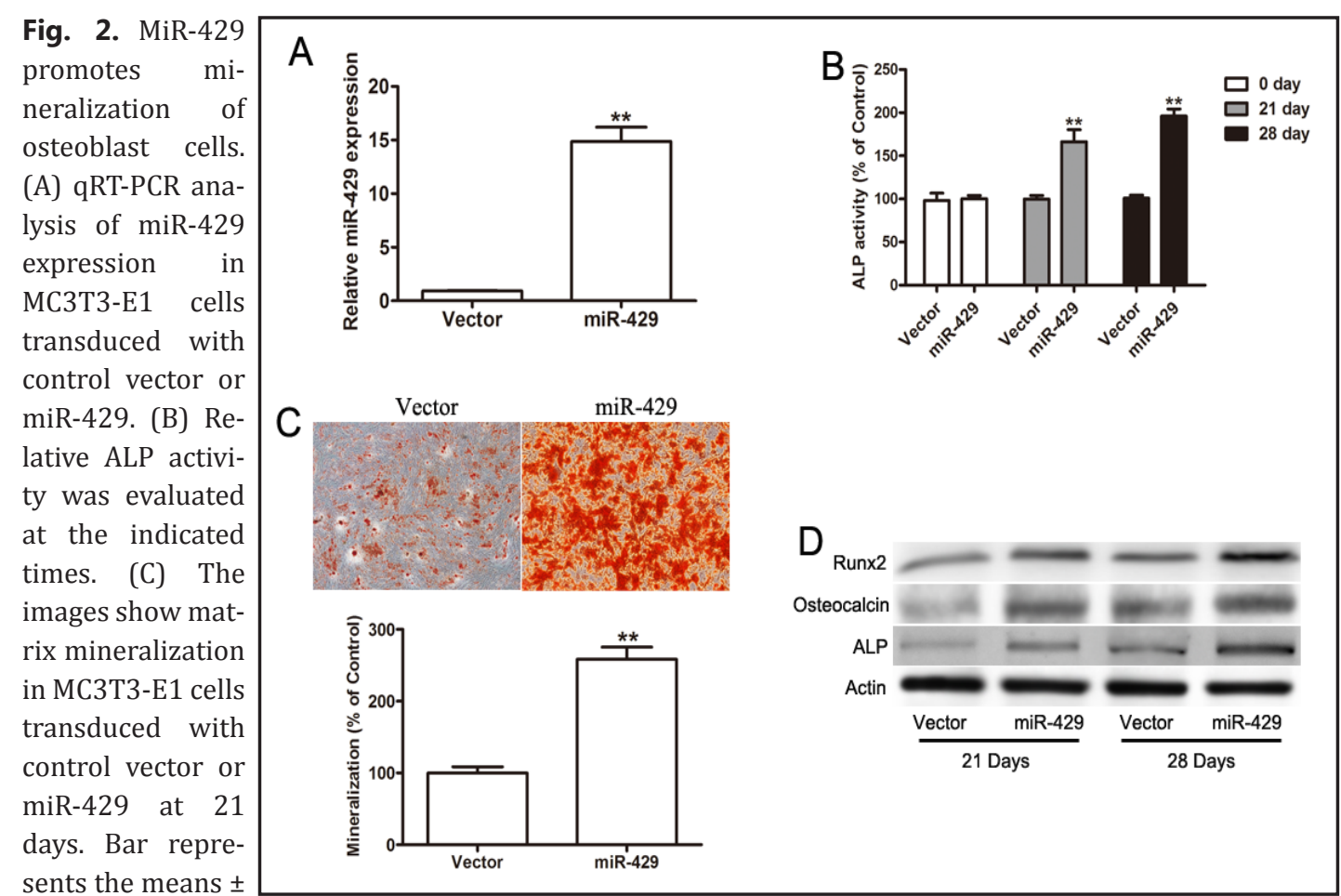
sents the means \pm SD. (D) Western blot analysis of ALP, OC and RUNX2 expression in MC3T3-E1 cells transduced with control vector or miR-429 at the indicated time. ${ }^{* *}, \mathrm{P}<0.01$.

Fig. 3. The negative regulation of ZFPM2 by miR-429. (A) The sequences of the putative miR-429 binding sites in wild type and mutant ZFPM2 3' UTR. (B) Luciferase activity analysis in the presence of wild type or mutant ZFPM2 3' UTR with control vector or miR-429. (C and D) The mRNA and protein levels of ZFPM2 were measured in miR-429-stably expressing MC3T3-E1 cells. (E) The relative expression of ZFPM2 mRNA was analyzed in MC3T3-E1 cells treated with $200 \mu \mathrm{M}$ $\mathrm{CoCl}_{2}$ at the indicated time. ${ }^{* *}, \mathrm{P}<0.01$.

\section{$A_{\text {zfpm2-utr }}$ \\ MUT1 5'-AAUUUAUUUUACCAGCACCCCUC-3' WT 5'-AAUUUAUUUUACCAGCAGUAUUC-3' II IIII I II III | \\ mmu-miR-429 3'-UGCCGUAAUGGUC-UCAUAAU-5' \\ ZFPM2-UTR \\ MUT2 5'-CAAAAUUACUGGAAGCACCCCUG-3' WT 5'-CAAAAUUACUGGAAGCAGUAUUG-3' II III II \\ mmu-miR-429 3'-UGCCGUAAUGGUCU--GUCAUAAU-5'}
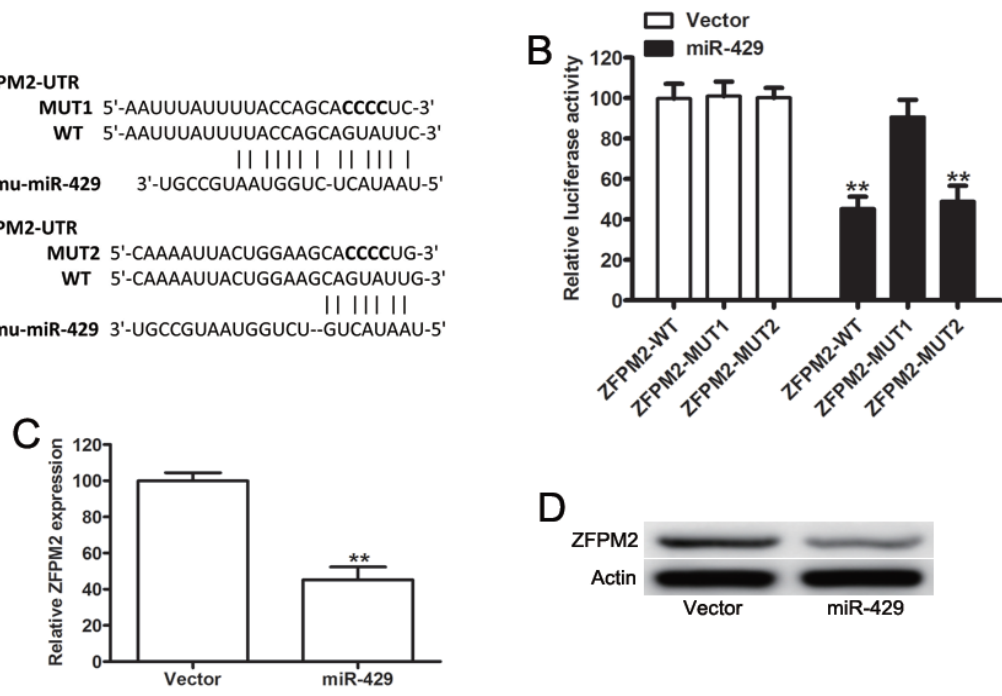

D

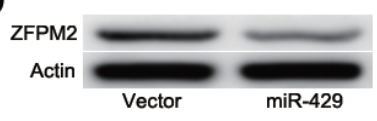

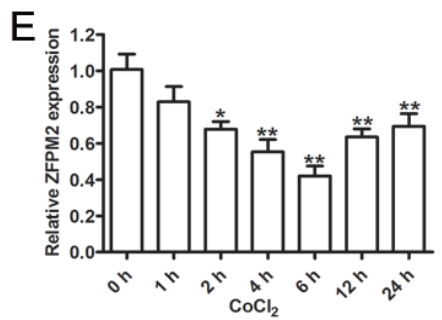


Fig. 4. ZFPM2 silencing promotes osteoblast differentiation. (A) Western blot analysis of ZFPM2 in MC3T3-E1 cells transfected with siRNA targeting ZFPM2. (B) Detection of ALP activity in MC3T3-E1 cells transfected with NC or siZFPM2 at the indicated time. (C) Matrix mineralization was examined by Alizarin red $\mathrm{S}$ staining in MC3T3-E1 cells transfected with NC or sizFPM2 at 21 days. (D) Analysis of GATA4, ALP, OC and RUNX2 expression in MC3T3-E1 cells transfected with NC or sizFPM2 by western blotting. $* *, \mathrm{P}<0.01$.

Fig. 5. MiR-429 promotes fracture healing in vivo. (A) Radiographic images of the fractured callus at 28 days in mice treated with or without miR-429. (B) qRT-PCR analysis of miR429 expression in bone tissues from mice. (C) Analysis of ZFPM2, OC and RUNX2 expression in bone tissues from mice. **, $\mathrm{P}<0.01$.

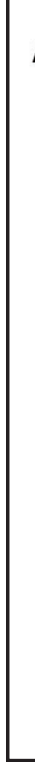
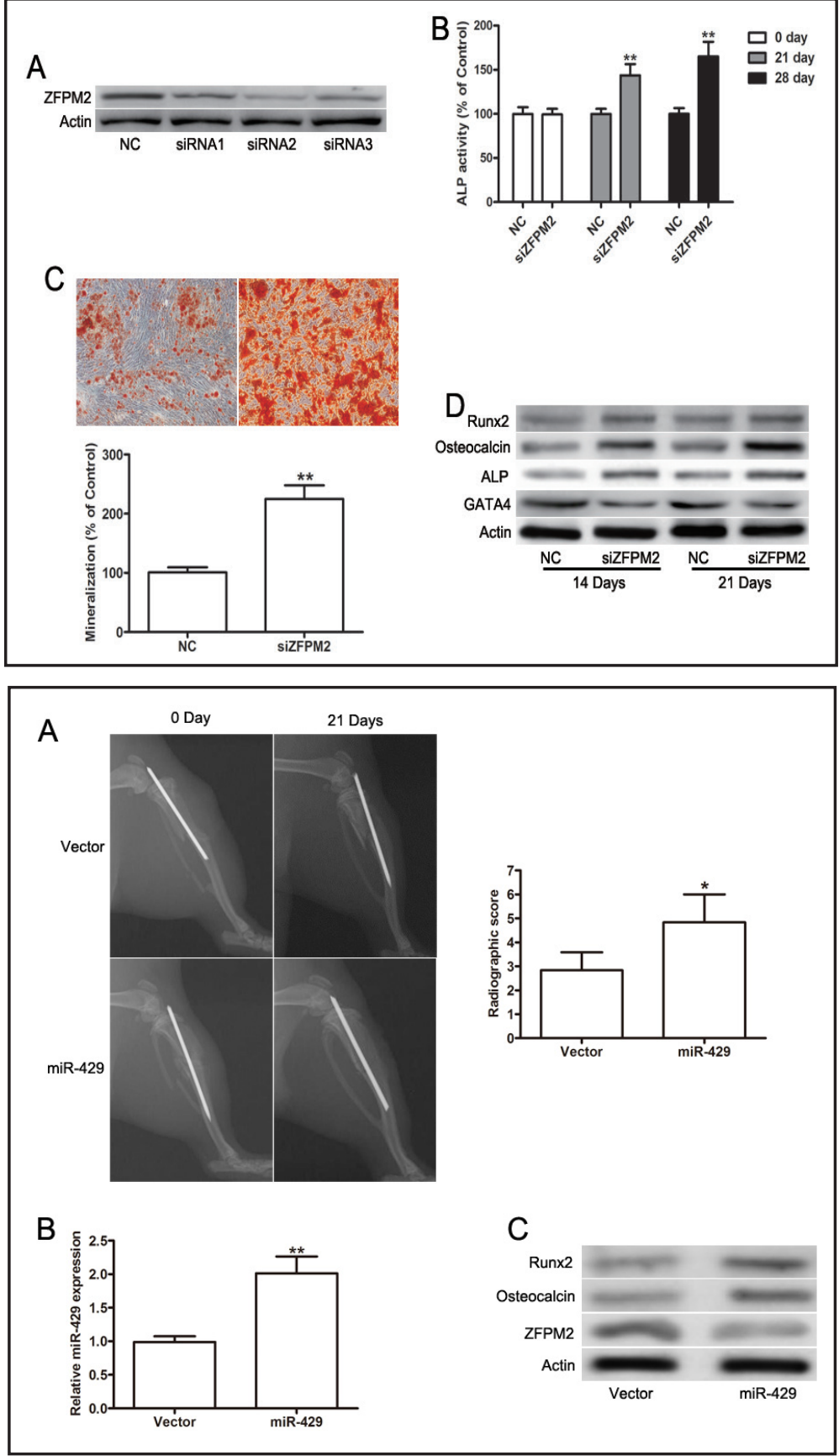

compared to the NC cells (Fig. 4C). It has been reported that ZFPM2 interacts with GATA4 to regulate heart development, and GATA4 has been reported to negatively regulate osteoblast differentiation by downregulation of Runx2 $[17,18]$. Subsequently, the expression of GATA4 and osteogenic marker genes (ALP, OC and RUNX2) were determined in ZFPM2 knockdown cells. ZFPM2 silencing strongly induced the expression of ALP, OC and RUNX2 and resulted in a decrease of GATA4. These findings suggested that ZFPM2 was involved in regulating osteoblast differentiation through regulation of GATA4 expression.

MiR-429 accelerates the formation and remodeling of bone during fracture repair in vivo

To determine whether miR-429 could trigger fracture repair in vivo, as observed in cultured cells, Lentivirus was injected into the subcutaneous region of local fracture, and radiographic examination was taken after 28 days. MiR-429 was found to remarkably KARGER 


\section{Cellular Physiology Cell Physiol Biochem 2016;39:1177-1186 \begin{tabular}{l|l|l} 
and Biochemistry Published online: September 01, 2016 & $\begin{array}{l}\text { (c) 2016 The Author(s). Published by S. Karger AG, Basel } \\
\text { www.karger.com/cpb }\end{array}$ \\
\hline
\end{tabular} \\ Huang et al.: MiR-429 Promote Osteoblastic Differentiation}

enhance new bone formation during the course of fracture repair compared to control vector (Fig. 5A). qRT-PCR was performed to detect the expression of miR-429 in the bone tissue from mice infected with miR-429 or control lentivirus. As we expected, the expression of miR-429 was significantly increased in mice infected with the miR-429 lentivirus (Fig. 5B). These data imply that miR-429 could accelerate fracture healing in vivo.

\section{Discussion}

It has been shown that many molecules can inhibit bone resorption and enhance bone formation and repair [19-21]. Previous studies have shown that the activated Hypoxia Inducible Factor- $1 \alpha$ (HIF-1 $\alpha$ ) pathway plays an important role in regulating osteoclast differentiation [22, 23]. In addition, our recent study reported that a rat model of bone fracture treated with $\mathrm{CoCl}_{2}$ could augment fracture healing [4]. However, the underlying mechanisms have not been fully elaborated. In our present study, we focus on miR-429, a hypoxia-regulated gene, involved in $\mathrm{CoCl}_{2}$-mediated activation of cell differentiation in preosteoblastic cells.

The hypoxia-inducible factor (HIF) pathway has been considered a powerful stimulus under a variety of pathological conditions by influencing angiogenesis and cellular metabolism [24, 25]. A set of hypoxia-regulated microRNAs were identified under hypoxic stress and provided an approach to understand the relation between stress factors and gene expression control [16, 26, 27]. MiR-429 was increased under hypoxic stress, and miR-429 negatively regulated HIF-1 activity through a negative feedback loop in human endothelial cells [16]. In the present study, we demonstrate that miR-429 was also increased in response to hypoxia in osteoclast differentiation in vitro and in vivo. Importantly, overexpression of miR-429 was able to increase ALP activity and osteoblast mineralization in MC3T3-E1 osteoblasts, indicating that the positive effects of miR-429 cannot be explained by the $\mathrm{CoCl}_{2}-$ mediated fracture healing. In keeping with its role in regulation of osteoclast differentiation, overexpression of miR-429 could induce osteogenic marker genes that were increased by $\mathrm{CoCl}_{2}$ in vivo [4]. Overexpression of miR-429 in vivo also showed that it could enhance fracture healing. Of course, it was synergetic that miR-429 regulated the expression of HIF1A and VEGFA to promote angiogenesis [16].

ZFPM2, a multi-zinc finger protein, has been found to play important roles in cardiac development $[17,28]$. The interaction of ZFPM2 with GATA4 leads to the transcriptional repression of target genes, and a recent study has shown that GATA4 negatively regulates osteoblast differentiation by downregulation of Runx2 [18]. Our present report indicated that ZFPM2 silencing stimulated osteoclast differentiation as well as the upregulation of osteogenic marker expression and downregulation of GATA4 expression. In addition, we confirmed the direct interaction of miR-429 and the 3' UTR of ZFPM2 using a luciferase assay and showed that overexpression of miR-429 could effectively suppress the endogenous expression of ZFPM2.

In conclusion, we found that miR-429 was induced by $\mathrm{CoCl}_{2}$, and it promoted preosteoblastic cell differentiation, thus providing an explanation for hypoxia as a major stimulator of osteoclast differentiation. We additionally identified ZFPM2 as a direct target of miR-429 involved in osteoclast differentiation. Though miR-429 was induced by hypoxia or $\mathrm{CoCl}_{2}, \mathrm{CoCl}_{2}$ was just a tools drug to mimic hypoxia to activate HIF1 pathway. Further studies to identify key target genes of miR-429 in osteoblasts will advance our understanding of the bone formation process under hypoxic conditions.

\section{Acknowledgments}

This study was funded by the Natural Science Foundation of Beijing (7164263) and the National Natural Science Foundation (81541135). 


\section{Cellular Physiology Cell Physiol Biochem 2016;39:1177-1186 and Biochemistry \begin{tabular}{l|l} 
DOI: 10.1159/000447824 & (c) 2016 The Author(s). Published by S. Karger AG, Basel \\
www.karger.com/cpb
\end{tabular} \\ Huang et al.: MiR-429 Promote Osteoblastic Differentiation}

\section{Disclosure Statement}

We confirm that the manuscript has been read and approved by all named authors.

\section{References}

1 Bonar SK, Marsh JL: Tibial Plafond Fractures: Changing Principles of Treatment. J Am Acad Orthop Surg 1994;2:297-305.

2 Garcia-Balderas A, Beltran-Cota ER, Ruiz-Barrios JM, Caldera-Barbosa 0: [Results of the treatment of high energy tibial pylon fractures]. Acta Ortop Mex 2013;27:363-366.

3 Villasenor Villasenor LE, Olea Leyva MA, Rodriguez Flores R, Hernandez Lopez JL: [Clinical outcome of a bilateral tibial pylon fracture treated with a minimally invasive technique]. Acta Ortop Mex 2009;23:163166.

4 Huang J, Liu L, Feng M, An S, Zhou M, Li Z, Qi J, Shen H: Effect of CoCl(2) on fracture repair in a rat model of bone fracture. Mol Med Rep 2015;12:5951-5956.

5 Djuranovic S, Nahvi A, Green R: A parsimonious model for gene regulation by miRNAs. Science 2011;331:550-553.

6 Iwakawa HO, Tomari Y: The Functions of MicroRNAs: mRNA Decay and Translational Repression. Trends Cell Biol 2015;25:651-665.

7 Borchert GM, Lanier W, Davidson BL: RNA polymerase III transcribes human microRNAs. Nat Struct Mol Biol 2006;13:1097-1101.

8 Bushati N, Cohen SM: microRNA functions. Annu Rev Cell Dev Biol 2007;23:175-205.

9 Ma J, Lin J, Qian J, Qian W, Yin J, Yang B, Tang Q, Chen X, Wen X, Guo H, Deng Z: MiR-378 promotes the migration of liver cancer cells by down-regulating Fus expression. Cell Physiol Biochem 2014;34:22662274.

10 Qi L, Zhang Y: The microRNA 132 regulates fluid shear stress-induced differentiation in periodontal ligament cells through mTOR signaling pathway. Cell Physiol Biochem 2014;33:433-445.

11 Qiao W, Chen L, Zhang M: MicroRNA-205 regulates the calcification and osteoblastic differentiation of vascular smooth muscle cells. Cell Physiol Biochem 2014;33:1945-1953.

12 Li E, Zhang J, Yuan T, Ma B: MiR-143 suppresses osteogenic differentiation by targeting Osterix. Mol Cell Biochem 2014;390:69-74.

13 Jia J, Tian Q Ling S, Liu Y, Yang S, Shao Z: miR-145 suppresses osteogenic differentiation by targeting Sp7. FEBS Lett 2013;587:3027-3031.

14 Zhang J, Zhao H, Chen J, Xia B, Jin Y, Wei W, Shen J, Huang Y: Interferon-beta-induced miR-155 inhibits osteoclast differentiation by targeting SOCS1 and MITF. FEBS Lett 2012;586:3255-3262.

15 Li Z, Hassan MQ Jafferji M, Aqeilan RI, Garzon R, Croce CM, van Wijnen AJ, Stein JL, Stein GS, Lian JB: Biological functions of miR-29b contribute to positive regulation of osteoblast differentiation. J Biol Chem 2009;284:15676-15684.

16 Bartoszewska S, Kochan K, Piotrowski A, Kamysz W, Ochocka RJ, Collawn JF, Bartoszewski R: The hypoxiainducible miR-429 regulates hypoxia-inducible factor-1alpha expression in human endothelial cells through a negative feedback loop. FASEB J 2015;29:1467-1479.

17 Crispino JD, Lodish MB, Thurberg BL, Litovsky SH, Collins T, Molkentin JD, Orkin SH: Proper coronary vascular development and heart morphogenesis depend on interaction of GATA-4 with FOG cofactors. Genes Dev 2001;15:839-844.

18 Song I, Kim K, Kim JH, Lee YK, Jung HJ, Byun HO, Yoon G, Kim N: GATA4 negatively regulates osteoblast differentiation by downregulation of Runx2. BMB Rep 2014;47:463-468.

19 Street J, Bao M, deGuzman L, Bunting S, Peale FV, Jr., Ferrara N, Steinmetz H, Hoeffel J, Cleland JL, Daugherty A, van Bruggen N, Redmond HP, Carano RA, Filvaroff EH: Vascular endothelial growth factor stimulates bone repair by promoting angiogenesis and bone turnover. Proc Natl Acad Sci U S A 2002;99:9656-9661.

20 Koyama T, Kamemura K: Global increase in 0-linked N-acetylglucosamine modification promotes osteoblast differentiation. Exp Cell Res 2015;338:194-202. 
21 Yin X, Wang X, Hu X, Chen Y, Zeng K, Zhang H: ERbeta induces the differentiation of cultured osteoblasts by both Wnt/beta-catenin signaling pathway and estrogen signaling pathways. Exp Cell Res 2015;335:107-

114.

22 Raheja LF, Genetos DC, Yellowley CE: Hypoxic osteocytes recruit human MSCs through an OPN/CD44mediated pathway. Biochem Biophys Res Commun 2008;366:1061-1066.

23 Wan C, Gilbert SR, Wang Y, Cao X, Shen X, Ramaswamy G, Jacobsen KA, Alaql ZS, Eberhardt AW, Gerstenfeld LC, Einhorn TA, Deng L, Clemens TL: Activation of the hypoxia-inducible factor-1alpha pathway accelerates bone regeneration. Proc Natl Acad Sci U S A 2008;105:686-691.

24 Semenza GL: Life with oxygen. Science 2007;318:62-64.

25 Zhdanov AV, Waters AH, Golubeva AV, Papkovsky DB: Differential contribution of key metabolic substrates and cellular oxygen in HIF signalling. Exp Cell Res 2015;330:13-28.

26 Li W, Chen YQ, Shen YB, Shu HM, Wang XJ, Zhao CL, Chen CJ: HIF-1alpha knockdown by miRNA decreases survivin expression and inhibits A549 cell growth in vitro and in vivo. Int J Mol Med 2013;32:271-280.

27 Sun KT, Chen MY, Tu MG, Wang IK, Chang SS, Li CY: MicroRNA-20a regulates autophagy related proteinATG16L1 in hypoxia-induced osteoclast differentiation. Bone 2015;73:145-153.

28 Pikkarainen S, Tokola H, Kerkela R, Ruskoaho H: GATA transcription factors in the developing and adult heart. Cardiovasc Res 2004;63:196-207. 